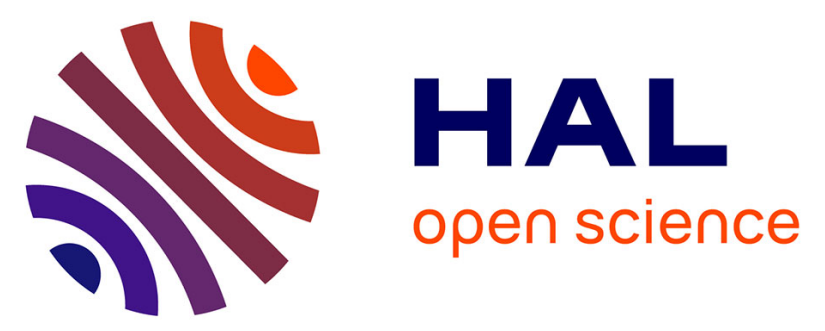

\title{
Medical and sociodemographic risk factors for preterm birth in a French Caribbean population of African descent.
}

Florence Rouget, Jennifer Lebreton, Philippe Kadhel, Christine Monfort, Florence Bodeau-Livinec, Eustase Janky, Luc Multigner, Sylvaine Cordier

\section{To cite this version:}

Florence Rouget, Jennifer Lebreton, Philippe Kadhel, Christine Monfort, Florence Bodeau-Livinec, et al.. Medical and sociodemographic risk factors for preterm birth in a French Caribbean population of African descent.. Maternal and Child Health Journal, 2013, 17 (6), pp.1103-11. 10.1007/s10995-0121112-x . hal-00860340

HAL Id: hal-00860340

https://hal-univ-rennes1.archives-ouvertes.fr/hal-00860340

Submitted on 10 Sep 2013

HAL is a multi-disciplinary open access archive for the deposit and dissemination of scientific research documents, whether they are published or not. The documents may come from teaching and research institutions in France or abroad, or from public or private research centers.
L'archive ouverte pluridisciplinaire HAL, est destinée au dépôt et à la diffusion de documents scientifiques de niveau recherche, publiés ou non, émanant des établissements d'enseignement et de recherche français ou étrangers, des laboratoires publics ou privés. 


\section{Medical and sociodemographic risk factors for preterm birth in a French Caribbean population of African descent}

F. Rouget, J. Lebreton, P. Kadhel, C. Monfort, F. Bodeau-Livinec, E. Janky, L. Multigner, S. Cordier

F. Rouget $(\boldsymbol{\&}) \cdot$ P. Kadhel $\cdot$ C. Monfort · F. Bodeau-Livinec $\cdot$ L. Multigner $\cdot$ S. Cordier

Epidemiological Research on Environment, Reproduction and Development, Institut National de la Santé et de la Recherche Médicale (INSERM), U1085, Campus de Beaulieu, 35042 Rennes cedex, France

e-mail: florence.rouget@univ-rennes1.fr

F. Rouget $\cdot$ P. Kadhel $\cdot$ C. Monfort $\cdot$ L. Multigner $\cdot$ S. Cordier

Institut de Recherche Santé Environnement \& Travail (IRSET), University Rennes 1, 35042 Rennes cedex, France

F. Rouget $\cdot$ J. Lebreton

Department of Pediatrics, CHU Rennes, 35203 Rennes cedex 2, France

P. Kadhel · E. Janky

Department of Obstetrics and Gynaecology, CHU Pointe-à-Pitre, 97159 Pointe à Pitre, Guadeloupe, France

F. Bodeau-Livinec

Department of Environmental and Occupational Health, School of Public Health (EHESP), 35043 Rennes cedex, France

E. Janky

University Antilles-Guyanes, 97157 Pointe-à-Pitre, Guadeloupe, France 


\begin{abstract}
There appears to be an incompressible high rate of preterm births among populations of African origin irrespective of their geographic location. The objective of this study was to assess the risk factors for preterm birth in a French Caribbean population of African descent, offered medical care comparable to that on the French mainland, but presenting a higher rate of preterm birth. The study was based on a birth cohort at maternity hospitals in Guadeloupe (French West Indies) including 911 singleton pregnancies enrolled during their third trimester check-up visits. Associations between risk factors and the risk of preterm delivery (spontaneous and induced) were assessed using a multivariate Cox model. In addition, prevalences of sociodemographic and medical factors in Guadeloupe were compared with those on the French mainland. 144 women $(15.8 \%)$ delivered preterm, medically induced in $52 \%$. Women delivering preterm were more often over 35 years old $(37 \%)$, single $(54 \%)$, and had higher prevalence of prior preterm birth (20\%), prior miscarriage (37\%), lupus (3\%), asthma (14\%), gestational hypertension (26\%), gestational diabetes (13\%) and urinary tract infection $(24 \%)$ than women with term births. In the whole cohort, these risk factors were also more frequent than in mainland France. Our results suggest highly prevalent medical risk factors for preterm births in Guadeloupe. This observation combined with specific social risk factors (older maternal age, single living) less frequent on the French mainland probably explains a large part of a higher prevalence of preterm births in this population despite similar medical provision.
\end{abstract}

Keywords Preterm birth $\cdot$ Induced preterm birth $\cdot$ Spontaneous preterm birth $\cdot$ Caribbean $\cdot$ Risk factor

\title{
Introduction
}

The population of Guadeloupe, a French Caribbean Archipelago, is largely of African descent. The French National Perinatal survey, conducted periodically on a representative sample of births, reported a prevalence in 2003 of $9.7 \%$ for preterm births in the French overseas territories including Guadeloupe, whereas the prevalence was $5.8 \%$ in mainland France [1]. This difference was also seen in a multiethnic population in an area near Paris where women born in the French West Indies had a higher prevalence of preterm births (7.9\%) than either women born in mainland France $(4.6 \%)$ or women of all other origins except those born in sub-Saharan Africa [2]. An incompressible high rate of preterm births seems to be a common feature of populations of African origin, irrespective of their current geographic location (USA, Caribbean, or Africa) and independent of socioeconomic status and obstetrical care [3]. This higher rate of preterm birth in populations of African origin is not fully under- stood. A number of maternal or fetal characteristics have been reported to be associated with spontaneous or medically indicated preterm birth [4-6].

Disentangling the respective contributions of maternal, medical and sociodemographic risk factors in a population of African descent with same health care access as that available on the French mainland may therefore help to elucidate the mechanisms involved. This may also provide clues for improving prevention.

We exploited the opportunity provided by the creation of a prospective epidemiological mother-child cohort (TIMOUN study) conducted by the French National Institute for Health and Medical Research (Inserm) in Guadeloupe. This birth cohort was established in 2006 to study the impact on pregnancy outcome and child development of prenatal exposure to the widespread pesticide pollution in Guadeloupe.

We collected personal medical and socioeconomic data, to compare the prevalence of risk factors in Guadeloupe with that on the French mainland and to study risk factors for preterm birth specific to this population.

\section{Methods}

The analysis was based on the TIMOUN birth cohort established in Guadeloupe (French West Indies). Between 2004 and $2007,1,068$ women attending check-up visits at public hospitals or dispensaries during their third trimester of pregnancy and having resided in Guadeloupe for more than 3 years were enrolled in the cohort. The refusal rate was about $7 \%$, and the most common reasons were: refusal of the spouse, did not wish to participate in the follow-up, or did not wish to provide biological samples. The biological specimens collected were maternal blood and cord blood during pregnancy, and maternal milk samples at 3 months; they were used to evaluate perinatal exposure to major organic pollutants and fatty acids. Participants provided written informed consent for participation, and the study was approved by the Guadeloupean Ethics Committee for studies involving human subjects.

At enrolment, the participants completed a standardized questionnaire during a face-to-face interview with mid- wives. The questionnaire covered sociodemographic characteristics (level of education, mother's and father's occupation, single living or not), medical and obstetrical history, and various lifestyle factors (tobacco, alcohol and drug consumption, diet during pregnancy and use of chemical products at work or at home). Alcohol consumption during pregnancy was ascertained 
on two occasions: during the interview at enrolment and after delivery.

After delivery, information was collected from midwives, pediatricians and hospital medical records about the medical history of the pregnancy, delivery, perinatal conditions, measurements and health status of the newborn at birth. Pre- term birth was defined as a birth before 37 completed weeks of gestation [7]. Gestational age was estimated by the obstetricians in charge of the follow-up of the women from last menstrual dates and corrected by the early first-trimester ultrasound in cases of discrepancy in estimation of more than 1 week; in such cases, the early first-trimester ultrasound estimation was retained. Preterm births were classified into two clinical subtypes, according to the mechanism of onset of the delivery: spontaneous or induced $[4,8]$. Spontaneous preterm birth results from the spontaneous onset of labor or membrane rupture, independent of the mode of delivery (vaginal delivery or caesarean section). Medically induced preterm birth results from induction of delivery by the clinician due to maternal or fetal factors, either by medication or by caesarean section, before the onset of spontaneous labor [4].

Various potential risk factors were investigated. Sociodemographic and lifestyle characteristics included maternal place of birth, age $(<20,20-34, \geq 35)$, marital status, years of education $(<5,5-12, \geq 12)$, employment during pregnancy (yes, no), tobacco consumption during pregnancy (yes, no), alcohol consumption during pregnancy (yes $=$ at least one drink during preceding week or one "binge drinking" session during the previous 3 months reported in the questionnaire administered at enrolment or the questionnaire administered after delivery, no). The woman's marital status was classified into three categories corresponding to family profiles common in Guadeloupe: single, living with partner, and single but living with family (an adult member of her family, typically mother, father, sister, or aunt). Medical factors included clinical and reproductive history [parity defined as the number of previous viable pregnancies $(0,1, \geq 2)$, prior preterm birth $(0,1, \geq 2)$, prior induced abortion including voluntary and medical termination of pregnancy $(0,1, \geq 2)$, prior miscarriage $(0,1, \geq 2)$ ], timing of first ultrasound (in weeks of gestational age), presence of maternal disease and particularly lupus, asthma, hypertension before or during pregnancy, diabetes before or during pregnancy, first trimester metrorrhagia, urinary tract infection and vaginal infection during pregnancy, sex of the newborn (male, female), and body mass index (BMI kg/ $\mathrm{m}^{2}$ ) before pregnancy. BMI was classified into three groups: underweight $(<18.5)$, normal weight $(18.5-25)$, overweight $(>25)$. Average weekly weight gain was calculated as the difference between the weight at inclusion (on average $27 \mathrm{WG)} \mathrm{and} \mathrm{the} \mathrm{prepregnancy} \mathrm{weight,} \mathrm{divided} \mathrm{by} \mathrm{the}$ number of weeks of gestation at inclusion. We chose the weight at inclusion rather than at delivery because we did not have measures for each woman at delivery; this approach also avoided the period of non linear weight gain in late pregnancy. Weekly weight gain was categorized into three groups (low, medium, high), with cut-off points similar to those used in other studies [9].

The analysis of determinants of preterm birth was restricted to women born in the Caribbean (Guadeloupe, Martinique, Haiti, Dominica) $(\mathrm{n}=958)$. Cases involving multiple births $(\mathrm{n}=25)$, major birth defects $(\mathrm{n}=8)$ and induced pregnancies after fertility treatment $(n=15)$ were excluded, resulting in a study sample of 911 women.

Associations between individual risk factors and the risk of preterm birth (total preterm, spontaneous preterm, medically induced preterm birth) relative to term birth, were first estimated by calculating a hazard ratio (HR) using a Cox model accounting for left truncation that is a possible con- sequence of inclusion during late pregnancy [10]. Risk factors associated with preterm birth of at least one group $(\mathrm{p}<0.20)$ were then entered into a full multivariate Cox model. Maternal age and level of education were also systematically included in the model. For covariates with more than $2 \%$ of values missing, an additional dummy category was created in the multivariate model. Adjusted hazard ratios and their $95 \%$ confidence intervals were estimated. SAS statistical software (SAS Institute, Cary, NC, USA) was used for all statistical analyses.

In addition to internal comparison, the frequencies of risk factors were compared between Guadeloupe and the French mainland, where appropriate data were available from the French National Perinatal Survey [1], a representative sample of all births in France in 2003.

\section{Results}

Most women of our sample were born in the French West Indies (Table 1). About two thirds of them were enrolled at the University hospital.

Among the 911 women, $144(15.8 \%)$ delivered preterm: 68 of them $(47.2 \%)$ were spontaneous preterm births, 75 $(52.1 \%)$ were medically induced preterm births, and for one woman the type of preterm birth could not be traced. Among the preterm births, $135(94 \%)$ were born after 32 weeks of gestation. Gestational weeks at enrollment did not differ between spontaneous and induced preterm births and term births ( $27.2 \pm 3$ weeks). The timing of the first ultrasound, considered as a marker of adequate medical follow-up of pregnancy, was on average 11.9 weeks of gestation, and similar for preterm and term births. In our sample, there was no evidence of a difference in the length of pregnancy between spontaneous and induced preterm births. The global proportion of deliveries by caesarean section was close to $26 \%$. It was $54 \%$ for induced preterm births and $31 \%$ for spontaneous preterm births.

The only sociodemographic factors that were associated with the risk of preterm births were the site of inclusion 
(University Hospital) and being single (with or without family) (Table 1).

Maternal medical risk factors significantly associated with the risk of spontaneous preterm birth were prior preterm birth and lupus. The risk of induced preterm birth was increased among women with high BMI, high parity, prior miscarriage, asthma and chronic hypertension. It was reduced for women with prior induced abortion (Table 2). Low gestational weight gain was associated with the risk of spontaneous preterm birth and male babies were more likely than female to be spontaneously delivered before term (Table 3). Gestational hypertension and gestational diabetes were the main pregnancy conditions associated with induced preterm birth (Table 3).

In the multivariate model, most of the associations listed above remained significant (Table 4). For spontaneous pre- term birth, the strength of the associations increased for maternal age, living single with family, prior preterm birth, and urinary tract infection. For induced preterm birth, associations with maternal overweight, parity and chronic hypertension disappeared, whereas the risks associated with living single and prior preterm birth increased. Overall, the main risk factors identified for preterm births were older maternal age, living single, prior preterm birth, asthma, gestational hypertension and urinary tract infection.

We compared the prevalence of risks factors for preterm birth in our study population with that on the French mainland (Tables 1, 2 and 3). Various socio-demographic risk factors (Table 1) were much more prevalent than on the French mainland: older maternal age, being single, low level of education, being unemployed. However, some risk factors for preterm births were less prevalent than on the French mainland. For instance, tobacco smoking during pregnancy was rarely reported $(4.0 \%)$ and only $2.6 \%$ were classified as drinkers. Medical factors were also more frequent in the study population, particularly prior preterm birth, prior miscarriage, and hypertension (Table 2); and almost half of the mothers were classified as overweight $(\mathrm{BMI}>25)$. Several different diseases were frequently reported during pregnancy (Table 3).

\section{Discussion}

We report a high rate of preterm birth $(15.8 \%)$ in our cohort of pregnant women in Guadeloupe. This rate inconsistent with a previous estimate $(17.7 \%)$ based on births in the main maternity hospital in Guadeloupe in 1993/1994 [11]. It is higher than the estimate for all French overseas territories (9.7\%) including Guadeloupe, based on the representative sample of births studied by the French National Perinatal Survey, and is almost three times higher than the rate in mainland France reported by the same survey $(5.8 \%)$ [1]. We may have overestimated the rate of preterm birth, because our recruitment was mainly in maternities in public hospitals; in particular, the University hospital probably recruits pregnant women at higher risk of preterm birth. This may have led to oversampling of women suffering from diseases during pregnancy leading to a higher risk of preterm births. Indeed, a higher pro- portion of women in our sample than of women reported by the French Perinatal Survey presented with complications of pregnancy. Zeitlin et al. [2] also found that the proportion of women with hypertension during pregnancy was higher among those born in the French Caribbean and Indian Ocean than those born in mainland France. The higher prevalence of pregnancy complications in our sample than on the French mainland may thus be a con- sequence of both a selection bias of our population enrolled mainly in the University hospital and a true higher prevalence of some complications of pregnancy in this population of African origin. The proportion of preterm births resulting from induced deliveries (52\%) was much higher than that in continental France (33\%) and those reported in other surveys, and this again reflects the high prevalence of disease during pregnancy in our study population [4].

Medical conditions or history known to favour preterm birth, such as gestational hypertension (present in $12.0 \%$ of the pregnancies), gestational diabetes $(9.7 \%)$, and previous miscarriage $(27.5 \%)$, were very frequent in this population and were strongly associated with the risk of induced preterm birth, confirming the findings of Golden- berg et al. [4]. We also observed high risks associated with other medical conditions less well characterised as risk factors for preterm births, notably lupus and asthma. Lupus affected $1.2 \%$ of our cohort, whereas a rate of $0.12 \%$ has been reported among Caribbean women (of all ages) in Martinique by Deligny et al. [12]. This high frequency of lupus in our cohort may be because pregnancies in women with lupus are considered to be high risk pregnancies and are therefore referred to University Hospitals. We found lupus to be associated with an increased risk of spontaneous preterm birth. In previous reports, this association has been explained as a consequence of the high frequency of hypertension, preeclampsia and infections among women with lupus [13-15], which was not the case in our population. The prevalence of asthma in our cohort $(10.4 \%)$ was close to the recently estimated prevalence in the general population of Martinique $(8.8 \%)$ another, very similar, French West Indies Island [16]. Asthma is now recognized to be a risk factor for preterm birth and preeclampsia, although the physiopathogenic process involved is still a matter of debate [17]. The role of asthma medication is also the subject of discussion and Schatz et al. [18] reported an association between ingested corticosteroids, but not inhaled drugs, and the risk of preterm birth. In our population, asthma was more specifically associated with an increased risk of induced preterm birth. This association has been described in other studies, some of 
them reporting that women with asthma are more likely to require induction of labour, irrespective of the severity of their asthma [17, 19]. On the contrary, a detailed review interprets this association with the risk of preterm birth as being limited to severe or corticodependent forms of asthma [17]. This was not the case in our population, in which no complications of asthma during pregnancy were reported. This issue deserves further investigation. The significant association between the risk of spontaneous preterm birth and urinary tract infections is consistent with previous reports concerning black populations [20,21]. Prior induced abortion was unexpectedly associated with a decreased risk of spontaneous preterm birth [22]. There are several possible reasons for this result. First, an under- declaration of prior abortion for social or emotional reasons is possible. Also, some declarations of miscarriage may, in reality, refer to disguised voluntary abortion (by self-prescription). Finally, the sociodemographic profile of the women in our study declaring prior induced abortion is very different from that generally observed for subgroups of this type (except from being more often single): they were older and not less educated than those without prior induced abortion, and they more often already had children.

Generally, adolescents and women over the age of 35 years are considered to be at increased risk of preterm birth. However, this association is the subject of debate and is difficult to study independently of the other socioeconomic and medical characteristics of women at the extremes of maternal age [23]. In our study, young maternal age $(<20$ years) was not a risk factor for preterm birth, although older age ( $>35$ years) was associated with an increased risk of spontaneous preterm birth. Our findings confirm a previous study in Guadeloupe among women under 18 years old showing no excess risk of preterm birth in this age group [11]. This previous study suggested that one explanation for the results was the adequate follow-up of even very young women, independent of socioeconomic status due to free access to health care [11].

Our data do not show any association with mother's education level or employment during pregnancy [24-26]. However, the number of women of low level of education in our study was small, such that the analysis had little power. We identified two categories of marital status, single mothers (living on their own) and single women living with their families, that were associated with a risk of preterm birth. The particular vulnerability of single women has already been repeatedly demonstrated [27, 28].

In our study, we identified another category, specific to our population: single women living with their family. These women may be subject to an accumulation of psychosocial risk factors, as was suggested in a previous study in Guadeloupe [29]. Further investigations including more detailed socioeconomic data are required to describe these women better and identify what makes them particularly vulnerable. The mechanisms by which sociodemographic factors may play a role in the risk of preterm birth have not been elucidated. Several authors have suggested that maternal psychosocial stress linked to poor living conditions may contribute [4, 30]. It is possible that there is a hormonal and inflammatory response to stress that involves the induction, via secretion of placental CRH (Corticotropin-Releasing-Hormone), of the secretion of prostaglandins that play a role in the induction of labor.

The number of women in our population identified as smoking tobacco, drinking alcohol or consuming illicit drugs was very low, which may explain why we did not see an association between these factors and preterm birth. This low prevalence has been confirmed by a survey con- ducted recently among young Guadeloupean adults, showing consumption of these products to be two to four times lower than in mainland France [31].

In our study, spontaneous preterm birth was more likely for male than female babies. This result is consistent with previous reports of a greater male susceptibility to spontaneous preterm birth [32,33]. Such gender specificity has, however, rarely been observed in black populations. Some studies have described a higher incidence of premature preterm rupture of membranes among mothers carrying a male fetus [33]. In the EPIPAGE study (French very pre- term birth cohort), this male excess in spontaneous preterm birth was more marked for preterm labor than for pre- mature preterm rupture of membranes [34]. Various explanations involving the nature of the intrauterine environment (hormones, infections, hypertension) have been proposed, but the details of the mechanisms remain unknown [33]. In our cohort, hypertension was taken into account in the multivariate model and therefore cannot explain this male excess.

The high rate of preterm births among black women in the United States, persisting after adjustment for socio- economic status and level of obstetrical care, has been partly attributed to stress generated by racial discrimination [3]. Our findings in Guadeloupe do not seem to be consistent with this hypothesis, because racial discrimination in this society is mainly directed towards migrants from other Caribbean islands (mostly from Haïti and Dominica). This migrant community makes up $12.5 \%$ of our study population, but the rate of preterm birth in this group was not different from that for other women in Guadeloupe.

In conclusion, the analysis in our birth cohort suggests highly prevalent medical risk factors for preterm births in Guadeloupe. This observation combined with specific social risk factors (older maternal age, single living) that are more prevalent than on the French mainland probably explains a large part of a higher prevalence of preterm birth in this population despite similar medical provision. 
Acknowledgments Study was supported by the French National Health Directorate, the National Endocrine. Disruptor Research Programme, the French Agency for Food, Environmental and Occupa- tional Health \& Safety, and the Departmental Public Health Services of Guadeloupe. We thank Evelyne Delver, Josy Goudou, P. Lancelot, midwives, and maternity staff at the University hospital of Guadeloupe and the general hospital of Basse-Terre for collecting and forwarding data.

\section{References}

1. Blondel, B., Supernant, K., Du Mazaubrun, C., et al. (2006). Trends in perinatal health in metropolitan France between 1995 and 2003 : Results from the National Perinatal Surveys. Journal de Gynecologie, Obstetrique et Biologie de la Reproduction, 35,

373-387.

2. Zeitlin, J., Bucourt, M., Rivera, L., et al. (2004). Preterm birth and maternal country of birth in a French district with a multiethnic population. British Journal of Obstetrics and

Gynaecology, 111, 849-855.

3. Muglia, L. J., \& Katz, M. (2010). The enigma of spontaneous preterm birth. New England Journal of Medicine, 362, 529-535.

4. Goldenberg, R. L., Culhane, J. F., Iams, J. D., et al. (2008). Epidemiology and causes of preterm birth. Lancet, 371, 75-84.

5. Ananth, C. V., \& Vintzileos, A. M. (2006). Epidemiology of preterm birth and its clinical subtypes. The Journal of Maternal- Fetal \& Neonatal Medicine, 19, 773-782.

6. Windham, G., \& Fenster, L. (2008). Environmental contaminants and pregnancy outcomes. Fertility and sterility, 89 (2 Suppl), e111-e116 (discussion e117).

7. International statistical classification of diseases and related health problems. 10th revision, Vol 2. Geneva: World Health Organization. 1993.

8. Savitz, D. A., Dole, N., Herring, A. H., et al. (2005). Should spontaneous and medically indicated preterm births be separated for studying aetiology? Paediatric and Perinatal Epidemiology, 19, 97-105.

9. Nohr, E. A., Bech, B. H., Vaeth, M., et al. (2007). Obesity, gestational weight gain and preterm birth: A study within the Danish National Birth Cohort. Paediatric and Perinatal Epide- miology, 21, 5-14.

10. Howards, P. P., Hertz-Picciotto, I., \& Poole, C. (2007). Conditions for bias from differential left truncation. American Journal of Epidemiology, 165, 444-452.

11. Gallais, A., Robillard, P. Y., Nuissier, E., et al. (1996). Adoles- cence and pregnancy in Guadeloupe. 184 cases. Journal de Gynecologie, Obstetrique et Biologie de la Reproduction, 25, 523-527.

12. Deligny, C., Thomas, L., Dubreuil, F., et al. (2002). Lupus sys- témique en Martinique : enquête épidémiologique. Revue de Medecine Interne, 23, 21-29.

13. Mecacci, F., Pieralli, A., Bianchi, B., et al. (2007). The impact of autoimmune disorders and adverse pregnancy outcome. Seminars in Perinatology, 31, 223-226.

14. Lê Thi Huong, D. U., Wechsler, B., Piette, J. C., et al. et le groupe d'étude sur la grossesse lupique (1994). French register of lupus in pregnancy: The evaluation. Rev Med Interne, 15, 305-317.

15. Molokhia, M., Maconochie, N., Patrick, A. L., et al. (2007). Cross-sectional analysis of adverse outcomes in 1029 pregnancies of AfroCaribbean women in Trinidad with and without systemic lupus erythematosus. Arthritis Research and therapy, 9, R124.

16. Quénel, P., Flamnad, C., Delmas, M. C., et al. (2008). Prévalence de l'asthme en Martinique : résultats de l'enquête ESCAL. Bul- letin d'Alerte et de Surveillance Antilles Guyane, 8, 7-10.

17. Tan, K. S., \& Thomson, N. C. (2000). Asthma in pregnancy.American Journal of Medicine, 109, 727-733.

18. Schatz, M., Dombrowski, M. P., Wise, R., et al. (2004). The relationship of asthma medication use to perinatal outcomes. The Journal of Allergy and Clinical Immunology, 113, 1040-1045.

19. Sorensen, T. K., Dempsey, J. C., Xiao, R., et al. (2003). Maternal asthma and the risk of preterm delivery. Annals of Epidemiology, 13, 267272.

20. Mac Lean, A. B. (2001). Urinary tract infection in pregnancy. International Journal of Antimicrobial Agents, 17, $273-276$.

21. Fiscella, K. (1996). Racial disparities in preterm births. The role of urogenital infections. Public Health Reports, 111, $104-113$.

22. Shah, P. S., Zao, J., \& on behalf of Knowledge Synthesis Group of Determinants of Preterm/LBW Births. (2009). Induced ter- mination of pregnancy and low birthweight and preterm birth: A systematic review and meta-analyses. British Journal of Obstet- rics and Gynaecology, 116, 1425-1442.

23. Berkowitz, G. S., \& Papiernik, E. (1993). Epidemiology of pre- term birth. Epidemiologic Reviews, 15, 414-443.

24. Aveyard, P., Cheng, K. K., Manaseki, S., et al. (2002). The risk of preterm delivery in women from different ethnic groups. British Journal of Obstetrics and Gynaecology, 109, 894-899.

25. Howard, D. L., Marshall, S. S., Kaufman, J. S., et al. (2006). Variations in low birth weight and preterm delivery among blacks in relation to ancestry and nativity: New York City, 1998-2002. Pediatrics, 118, e1399-e1405.

26. Savitz, D. A., Kaufman, J. S., Dole, N., et al. (2004). Poverty, education, race, and pregnancy outcome. Ethnicity and Disease, 14, 322329.

27. Raatikainen, K., Heiskanen, N., \& Heinonen, S. (2005). Marriage still protects pregnancy. British Journal of Obstetrics and Gynaecology, 112, 1411-1416.

28. Zeitlin, J., Saurel-Cubizolles, M. J., Ancel, P. Y., \& Europop Group. (2002). Marital status, cohabitation, and risk of preterm birth in Europe: Where births outside marriage are common and uncommon. Paediatric and Perinatal Epidemiology, 16, 124-130.

29. De Caunes, F., Alexander, G. R., Berchel, C., et al. (1989). Un exemple de recherche-action sur la mortalité périnatale en Gua- deloupe. Facteurs et profils de risque socio-démographiques. Journal de Gynecologie, Obstetrique et Biologie de la Repro- duction, 18, 843-848.

30. Ancel, P. Y. (2002). Menace d'accouchement prématuré et travail prématuré à membranes intactes: Physiopathologie, facteurs de risque et conséquences. Journal of Gynecology Obstetrics Biol- ogy Reproduction, 31(7 Suppl), 5S10-5S21.

31. Beck, F., Legleye, S., Le Nezet, O., et al. (2007). Analyse régionale ESCAPAD 2005. OFDT.

32. Zeitlin, J., Saurel-Cubizolles, M. J., de Mouzon, J., et al. (2002). Fetal sex and preterm birth: Are males at greater risk? Human Reproduction, 17, 2762-2768.

33. Di Renzo, G. C., Rosati, A., Sarti, R. D., et al. (2007). Does fetal sex affect pregnancy outcome? Gender Medicine, 4, 19-30.

34. Zeitlin, J., Ancel, P. Y., Larroque, B., and the EPIPAGE group, et al. (2004). Fetal sex and indicated very preterm birth: Results of the EPIPAGE study. American Journal of Obstetrics and Gynecology, 190, 1322-1325. 


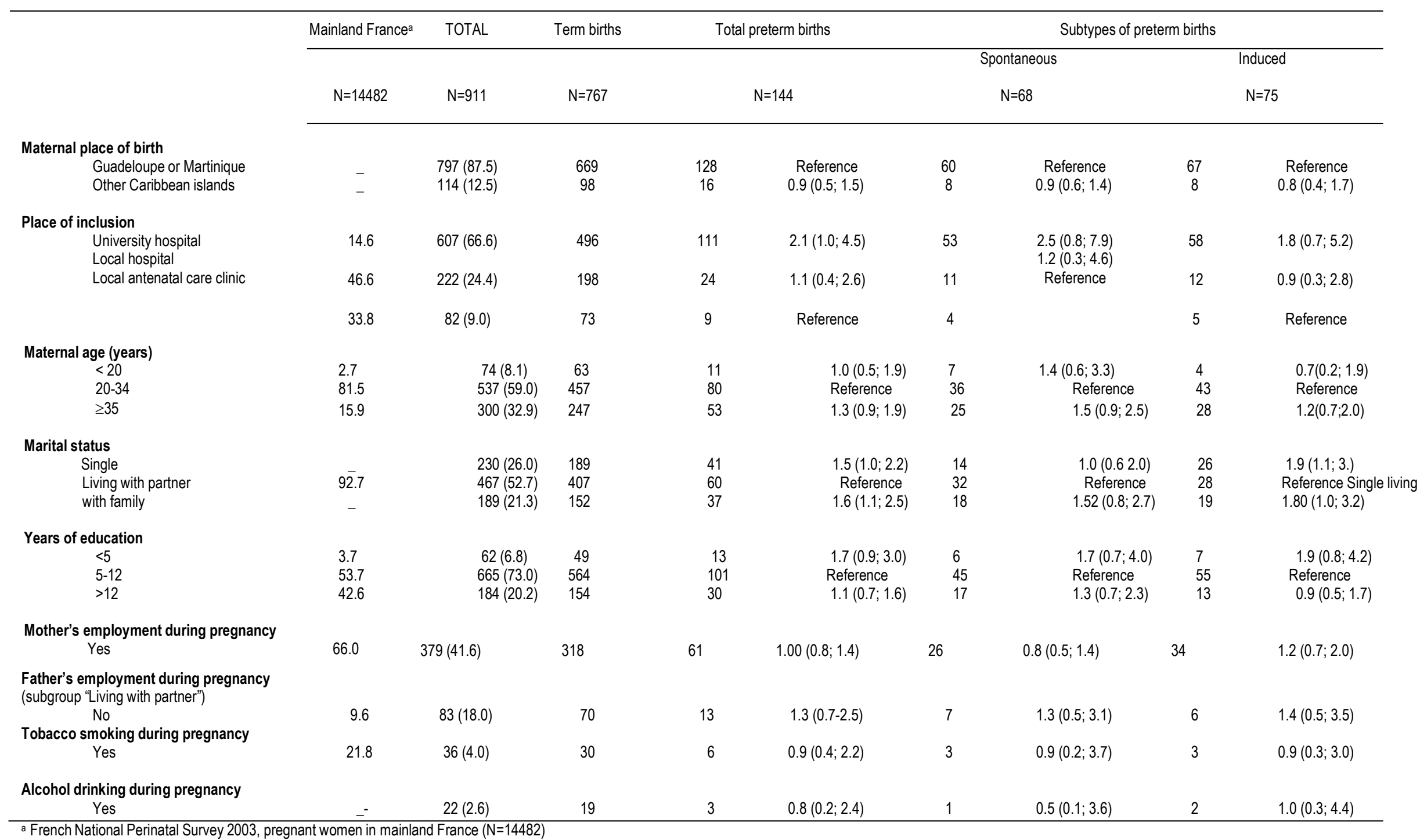

a French National Perinatal Survey 2003, pregnant women in mainland France $(\mathrm{N}=14482)$

${ }^{b} \mathrm{HR}$, Hazard Ratio: comparison between each group of preterm births and term births

${ }^{\circ} \mathrm{Cl}$, Confidence Interval 
Table 2: Distribution of maternal medical history in our study population and in mainland France, and associations with the risk of preterm birth

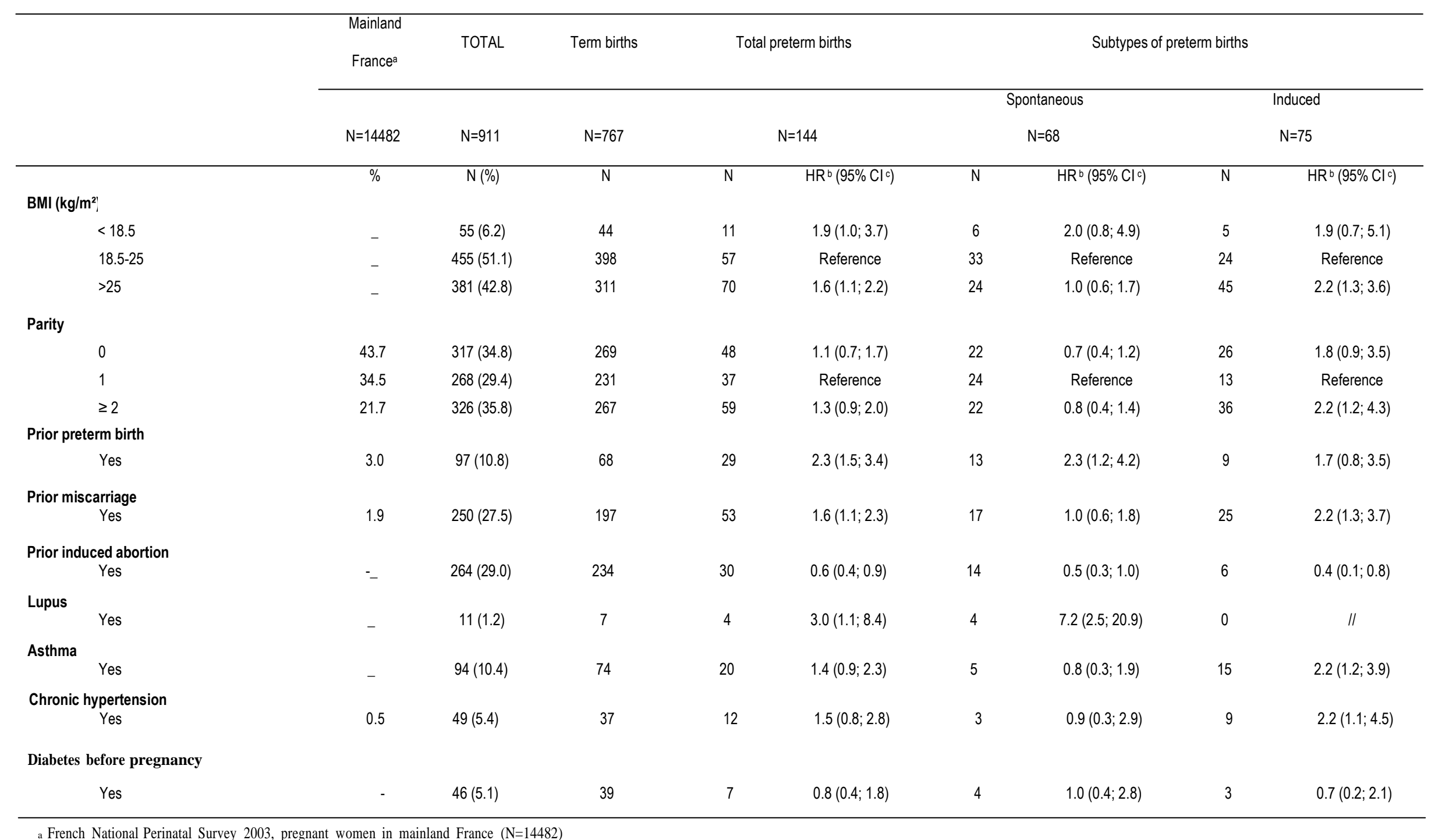

bHR, Hazard Ratio: comparison between each group of pretenn births and term births

c $\mathrm{Cl}$, Confidence Interval 
Table 3: Distribution of pregnancy characteristics in our study population and in mainland France, and associations with the risk of preterm birth

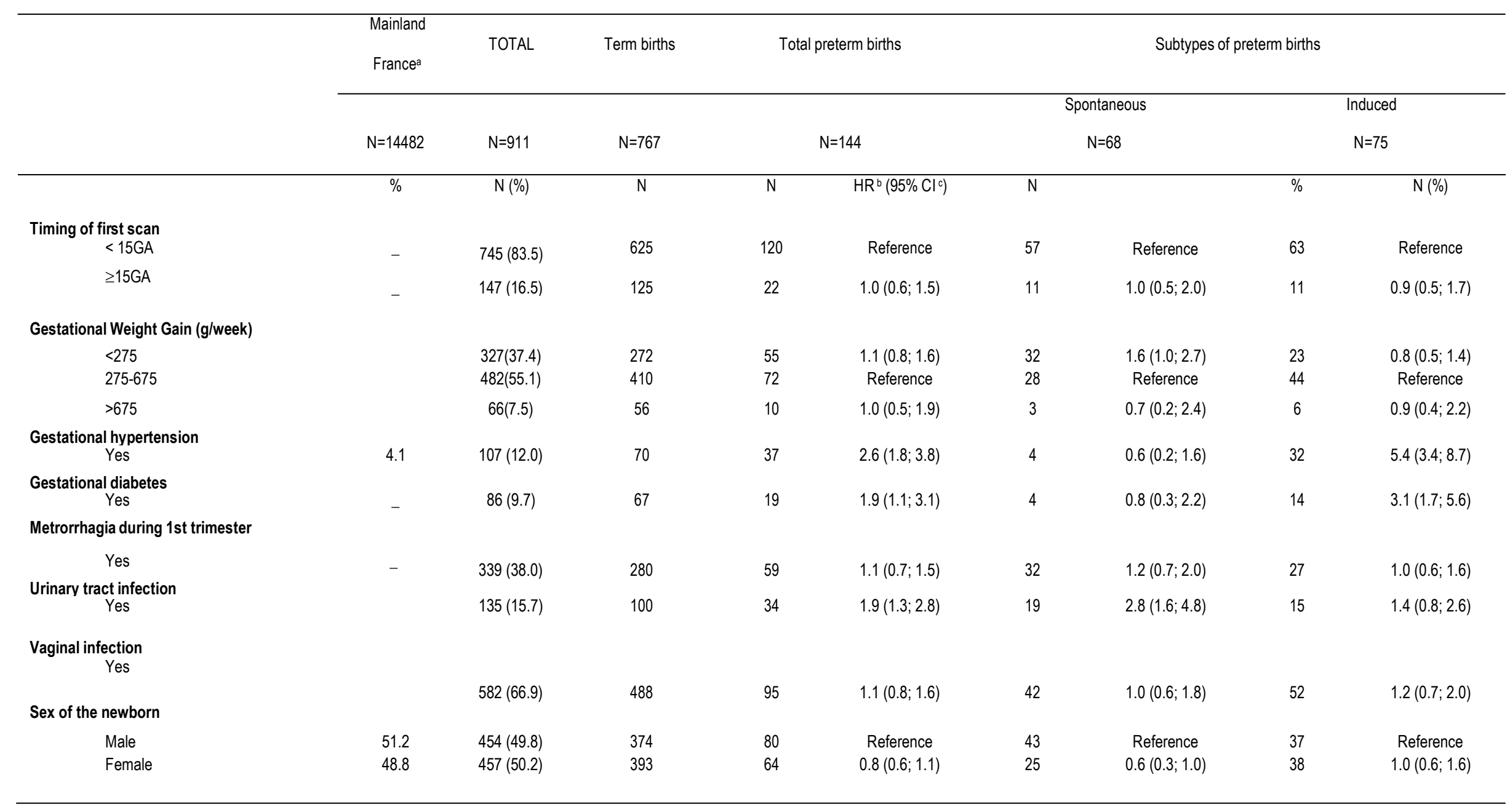

a French National Perinatal Survey 2003, pregnant women in mainland France (N=14482)

๖ HR, Hazard Ratio: comparison between each group of pretenn births and term births

$\mathrm{Cl}$, Confidence Interval 
Table 4. Multivariate analysis of the association between various risk factors and the risk of preterm birth according to subtype

\begin{tabular}{|c|c|c|c|c|c|c|c|}
\hline & \multirow{4}{*}{$\begin{array}{c}\text { Term births } \\
\text { N=767 } \\
\mathrm{N}\end{array}$} & \multicolumn{2}{|c|}{ Preterm births } & \multicolumn{4}{|c|}{ Subtype of preterm births } \\
\hline & & & & \multicolumn{2}{|c|}{ Spontaneous } & \multicolumn{2}{|r|}{ Induced } \\
\hline & & \multicolumn{2}{|r|}{$N=144$} & \multicolumn{2}{|r|}{$N=68$} & \multicolumn{2}{|r|}{$\mathrm{N}=75$} \\
\hline & & $\mathrm{N}$ & $\mathrm{HR}^{\mathrm{a}}\left(95 \% \mathrm{Cl}^{\mathrm{b}}\right)$ & $\mathrm{N}$ & $\mathrm{HR}(95 \% \mathrm{Cl})$ & $\mathrm{N}$ & $\mathrm{HR}(95 \% \mathrm{Cl})$ \\
\hline \multicolumn{8}{|l|}{ Place of inclusion } \\
\hline University hospital & 496 & 111 & $2.0(0.9 ; 4.4)$ & 53 & $3.5(1.0 ; 12.6)$ & 58 & $2.0(0.7 ; 6.2)$ \\
\hline Local hospital & 198 & 24 & $1.4(0.6 ; 3.5)$ & 11 & $2.2(0.5 ; 9.2)$ & 12 & $1.5(0.4 ; 5.4)$ \\
\hline Local antenatal care clinic & 73 & 9 & Reference & 4 & Reference & 5 & Reference \\
\hline \multicolumn{8}{|l|}{ Maternal age (years) } \\
\hline$<20$ & 63 & 11 & $0.9(0.5 ; 2.0)$ & 7 & $1.4(0.5 ; 4.0)$ & 4 & $0.1(0.2 ; 2.0)$ \\
\hline $20-34$ & 457 & 80 & Reference & 36 & Reference & 43 & Reference \\
\hline$\geq 35$ & 247 & 53 & $1.5(1.0 ; 2.2)$ & 25 & $2.4(1.3 ; 4.5)$ & 28 & $1.2(0.7 ; 2.3)$ \\
\hline \multicolumn{8}{|l|}{ Marital status } \\
\hline single & 189 & 41 & $1.6(1.0 ; 2.4)$ & 14 & $1.1(0.6 ; 2.3)$ & 26 & $2.5(1.4 ; 4.7)$ \\
\hline living in couple & 407 & 60 & Reference & 32 & Reference & 28 & Reference \\
\hline single living with family & 152 & 37 & $2.6(1.6 ; 4.2)$ & 18 & $2.5(1.2 ; 5.2)$ & 19 & $2.9(1.3 ; 6.1)$ \\
\hline \multicolumn{8}{|l|}{ Years of education } \\
\hline$<5$ & 49 & 13 & $1.5(0.7 ; 3.0)$ & 6 & $2.4(0.9 ; 6.6)$ & 7 & $1.9(0.7 ; 5.1)$ \\
\hline $5-12$ & 564 & 101 & Reference & 45 & Reference & 55 & Reference \\
\hline$>12$ & 154 & 30 & $1.3(0.8 ; 2.1)$ & 17 & $1.5(0.7 ; 2.9)$ & 13 & $1.1(0.6 ; 2.3)$ \\
\hline \multicolumn{8}{|l|}{ BMI $\left(\mathrm{kg} / \mathrm{m}^{2}\right)$} \\
\hline$<18.5$ & 44 & 11 & $1.9(0.9 ; 3.8)$ & 6 & $2.0(0.7 ; 5.5)$ & 5 & $2.1(0.8 ; 5.8)$ \\
\hline $18.5-25$ & 398 & 57 & Reference & 33 & Reference & 24 & Reference \\
\hline$>25$ & 311 & 70 & $1.2(0.8 ; 1.7)$ & 24 & $1.0(0.6 ; 1.9)$ & 45 & $1.3(0.7 ; 2.3)$ \\
\hline
\end{tabular}

\section{Parity}

0

1

$\geq 2$

Prior preterm birth

Yes

Prior miscarriage

Yes

\section{Prior induced abortions}

Yes
269
231
267

68

197

$53 \quad 1.2(0.8 ; 1.8)$
$0.5(0.3 ; 1.1) \quad 26$

Reference 13

$0.6(0.3 ; 1.2) \quad 36$

$1.8(0.9 ; 3.7)$

Lupus 
Asthma

Yes

Chronic hypertension

Yes

37

$$
12
$$$$
0.9(0.5 ; 1.9)
$$

94

210

129

$>675$

Gestational hypertension

Yes

70

37

$2.2(1.4 ; 3.5)$

67

$19 \quad 1.5(0.9 ; 2.6)$

4

$0.8(0.3 ; 2.4) \quad 14$

$2.3(1.2 ; 4.7)$

Urinary tract infection

Yes

100

$34 \quad 1.8(1.2 ; 2.7)$

$19 \quad 3.5(1.9 ; 6.4) \quad 15$

$1.1(0.6 ; 2.1)$

Sex of the newborn

$\begin{array}{lccccccr}\text { Male } & 374 & 80 & \text { Reference } & 43 & \text { Reference } & 37 & \text { Reference } \\ \text { Female } & 393 & 64 & 0.7(0.5 ; 1.0) & 25 & 0.5(0.3 ; 0.9) & 38 & 0.9(0.6 ; 1.5)\end{array}$

a HR, Hazard Ratio: comparison between each group of preterm births and term births

${ }^{\mathrm{C}} \mathrm{Cl}$, Confidence Interval 